\title{
La constitucionalidad del derecho a la agroecología como propulsor de los derechos humanos
}

Gladstone Leonel Júnior*

\section{INTRODUCCIÓN}

En América Latina se exalta el modelo del agronegocio, centrado en la propiedad latifundista, pautado en el monocultivo extensivo y dirigido al mercado de exportación, conforme lo puntuado. Incluso con toda la propaganda mediática, poniendo al sector agroexportador como el responsable de un significativo saldo positivo en la balanza comercial, no es posible ignorar a qué costos esas divisas externas se obtienen. La insostenibilidad es el concepto clave en la caracterización del agronegocio. El reflejo del incentivo a ese modelo repercute en aspectos económicos, sociales y ambientales. La alternativa al modelo del agronegocio no puede ser otra, sino la agroecología.

Ciertamente, al hablar de derechos humanos es necesario entenderlos como productos culturales surgidos en determinado momento histórico. Es decir, va más allá de las normas meramente positivadas o de los derechos naturales. De la misma forma que descrito en los análisis referenciados en el "derecho desde la calle" (SOUSA JÚNIOR, 2015), ellos son formas concretas del producto de luchas sociales! Estas "luchas a partir de las cuales nombramos y transformamos las experiencias son una de las cuestiones más fundamentales a la hora de hablar y practicar lo que convencionalmente denominamos como derechos humanos" (HERRERA FLORES, 2009, p. 86). La Constitución Federal, al asimilar esas luchas, como en el caso de la bandera de la agroecología, actúa como instrumento de efectuación de los derechos humanos, de ahí, su importancia.

\footnotetext{
* Professor adjunto da Faculdade de direito e do Programa de Pós-graduação em Direito constitucional da Universidade Federal Fluminense. Doutor e pós-doutor em direito pela Universidade de Brasília. Realizou o estágio doutoral na Facultat de Dret, Universitat de Valencia, Espanha. Membro da secretaria nacional do IPDMS - Instituto de Pesquisa, Direitos e Movimentos Sociais.
} 
En la Constitución brasileña, ya, en los principios fundamentales instituidos en nuestra República, se objetiva la construcción de una sociedad libre, justa y solidaria, garantizadora del desarrollo nacional. La dinámica de desarrollo agroecológico pasa por esas características, ya que busca el desarrollo en sus variados aspectos, y no sólo el crecimiento económico irracional, anhelando la construcción de un "derecho desde el campo". La centralidad de la sostenibilidad, en todos los aspectos, es una característica inherente al desarrollo de la agroecología. Así, permite que la solidaridad entre sus actores sea una práctica frecuente como consecuencia de los diversos métodos de trabajo que promueven tal intercambio de experiencias y de productos, como en el caso del intercambio de semillas y del fomento del mercado interno, por intermedio del trabajo de varios campesinos productores/as, y no de pocos latifundistas.

El objetivo de estos principios, establecidos en el artículo 3 de la Constitución, prevé la importancia de la erradicación de la pobreza con la reducción de las desigualdades sociales y regionales, promoviendo el bienestar de todos ${ }^{1}$. Justamente, por medio del fortalecimiento del mercado interno, la construcción agroecológica crea la condición para una mayor inclusión social, pues estimula la práctica de la reforma agraria y reduce la desigualdad, ya que la producción tenderá a aumentar, será más diversificada y realizada por un gran número de personas si se cumple el dispositivo constitucional. "Cabe destacar que "los beneficiarios de la reforma agraria tienen una renta anual equivalente a 3,7 salarios mínimos, mientras que los trabajadores sin tierra alcanzan, en promedio, sólo 0,7 del mínimo “(ROSSET, 2006, p. 328).

Esto, aún puede reflejar en una disminución del precio de alimentos, ya que con el cultivo de ellos hay un aumento de la oferta, lo que no ocurre en el modelo del agronegocio que privilegia su producción al mercado de exportación, conocido como commodities. Así, los objetivos reales de la República estarán, de hecho, posibilitados de ser cumplidos, necesitando de mejoras y de otros varios aspectos para que, estructuralmente, sean efectivizados.

De la misma forma, cuando la Constitución afirma que en las relaciones internacionales brasileñas el país deberá regirse, incluso por la prevalencia de los derechos humanos, muchos desdoblamientos se derivarán de esa asertiva constitucional ${ }^{2}$. Pues, a lo largo de la práctica agroecológica, se realiza tanto el derecho humano a la alimentación adecuada ya la tierra rural, como el derecho humano al medio ambiente, además de varios otros de forma menos explícita.

Con base en este artículo constitucional (artículo 4, inciso II), algunas normas internacionales son recibidas, sobre todo cuando se ratifican, para garantizar los derechos humanos. Al estar los derechos declarados, la fundamentación jurídica se vuelve explícita y las luchas populares ganan un respaldo en el derecho, aunque, en ese aspecto, limitado al positivismo.

En suma, la práctica de la agroecología sirve como instrumento de promoción de los derechos humanos y, consecuentemente, la concreción de los derechos humanos se da con la práctica agroecológica. 
Al resaltar la centralidad de la agroecología, consecuentemente también se resiste y se contrapone a otro proyecto dirigido al agribusiness. Un contrapunto histórico implementado en América Latina de más de 500 años de latifundio; explotación de fuerza de trabajo (incluso esclava, hasta los días de hoy); exportación de materias primas (commodities); destrucción ambiental; producción de alimentos caros y envenenados por agrotóxicos.

Por estas razones, la agroecología está justificada en América Latina y, evidentemente, en Brasil, como una construcción agroambiental que avanza en esta estructura histórica fracasada. Así como sería importante en otros continentes, ya que buscamos alternativas ambientalmente sostenibles y socialmente justas en la elección de futuros modelos agroambientales (LEONEL JÚNIOR, 2018, p. 253).

En pleno siglo XXI, todavía reproducimos prácticas semejantes a las del siglo XVI. Esas son prácticas violadoras de Derechos Humanos, pero en vez de tratar las violaciones provocadas, vamos a demostrar cómo la agroecología puede ser una práctica promotora de derechos humanos.

\section{LACENTRALIDADDELASOSTENIBILIDADAGROECOLÓGICA A PARTIR DE LA CONSTITUCIÓN}

A pesar de entender que el derecho debe trascender a un análisis positivista bajo la utilización de métodos formalistas corrientes en el universo jurídico, asumiendo, sí, una postura compleja y dinámica para animar las luchas sociales existentes, se pautará por ahora, en referenciar la agroecología bajo un enfoque constitucional.

$\mathrm{Al}$ observar las experiencias constitucionales recientes en América Latina, sobre todo aquellas protagonizadas por Bolivia, Ecuador y Venezuela, se percibe el inicio de una mayor reflexión en modificar las matrices del saber, de la política, de la economía y de la relación hombre/mujer/naturaleza. "Nuevas relaciones y formas de poder se construyen en este nuevo contexto" (LEONEL JÚNIOR, 2015, p. 103). La agroecología tiende a ser un instrumento dentro de un contexto donde se anhela modificar las estructuras y las relaciones establecidas, con las ideas decoloniales y desde un nuevo constitucionalismo latinoamericano. Un constitucionalismo que tiene la fuerza de enfrentar elementos de la modernidad, como la universalización de conceptos, la subalternidad de los pueblos latinos, el individualismo y la separación de la naturaleza y del ser humano, pudiendo contribuir al fortalecimiento de una matriz agroecológica que sigue el mismo rumbo. Es decir, una agroecología que absorbe el diálogo intercultural y garantice el pluralismo epistemológico.

Según lo destacado por Ramiro Ávila Santamaria, "por primera vez, y de manera aún excepcional, los juristas comienzan a integrar categorías como la colonialidad, la Pachamama y el Sumak Kawsay en sus análisis teóricos, a 
través de la noción de pluralismo jurídico “(2017, p. 24). Esto es una señal de comprensión de una cosmovisión, hasta entonces ignorada en la construcción del derecho, retirándolo de las hojas polvorientas de los códigos y materializándolo en la vida de las personas.

Incluso sin la explicitación del término agroecología, todos sus fundamentos están recibidos en la Constitución Federal Brasileña. Y, más que eso, su práctica constituye concreta promoción de los derechos humanos, como destacado. Con base en la Carta Magna, se buscará las garantías jurídicas debidas al desarrollo de la agroecología en Brasil y, por qué no, en toda América Latina. El rol de derechos fundamentales garantizados sobrepasa las libertades individuales del iluminismo y alcanza derechos sociales e incluso garantías difusas como la protección al medio ambiente (FARIA SANTOS, 2009, p. 62-64).

En el debate teórico sobre la fuerza normativa de la Constitución, incluso en los aportes eurocéntricos, se puede apuntar las fundaciones del prusiano Konrad Hesse, que desarrolló en una de sus obras, la argumentación de equilibrio de la existencia de la Constitución real y de la Constitución Jurídica. Esta fundamentación establece la diferencia de pensamiento entre Hesse y Ferdinand Lassalle sobre la esencia de la Constitución ${ }^{3}$, a pesar de que los autores han vivido estructuras políticas y económicas diversas, las cuales propiciaron al constitucionalismo del siglo XIX, un panorama diferenciado del desarrollado en el siglo XX.

Para Hesse, a partir del momento en que la Constitución esté en una consonancia concreta en el aspecto social e histórico con el pueblo que a ella está sometido, hay una fuerza normativa en su seno. De acuerdo con el autor:

A Constituição não está desvinculada da realidade histórica concreta do seu tempo. Todavia, ela não está condicionada, simplesmente, por essa realidade. Em caso de eventual conflito, a Constituição não deve ser considerada, necessariamente, a parte mais fraca. Ao contrário, existem pressupostos realizáveis que, mesmo em caso de confronto, permitem assegurar a força normativa da Constituição (HESSE, 1991, p. 25).

Por lo tanto, una Constitución promulgada, que propicie la efectividad de derechos humanos, por medio del desarrollo de la agroecología, por ejemplo, como puede ser considerada la brasileña, debe hacer valer su fuerza normativa para la concreción de esos dispositivos. La Constitución no se restringe al texto que presenta, pero sus asertivas también emanan de determinaciones históricas constituidas. Ella se revelará como un "instrumento político-jurídico de este cambio; que fija la dirección que debe ser seguida por la actuación de los sujetos constitucionales, sobre todo de los agentes estatales, que deben asumirse guiados, dirigidos por ella" (ESCRIVÃO FILHO, 2011, p. 57). 
Incluso teniendo un resguardo jurídico legal, en la realidad, la agroecología está fundamentada y legitimada en la práctica social de sus actores, los cuales enfrentan un modelo de agricultura hegemónico y violador, tanto de las leyes puestas como del medio ambiente y social.

El soporte constitucional permite evidenciar las garantías y los derechos humanos, tanto en el ámbito interno o incluso internacional. Esto posibilitará que la dinámica de las luchas sociales tengan, hasta, un mayor vigor jurídico en la perspectiva de asegurar la legitimidad. Más que eso, el sistema constitucional debe analizar los derechos humanos por una lente decolonial ya partir de las relaciones de producción establecidas con el propósito de garantizar su posibilidad real de cumplirlos.

Por cierto, esa búsqueda de derechos humanos es algo constante, cambiante de acuerdo con las sociedades y dialéctica, en su construcción, siguiendo el movimiento de la historia y la lucha de clases. Para José Geraldo de Sousa Júnior, es una posibilidad de ver los derechos, tal cual deben ser puestos en práctica, "como productos de luchas culturales, sociales, económicas y políticas para" ajustar "la realidad en función de los intereses más generales y difusos de una formación social" (2011, p. 36).

Con base en ese movimiento, nuevas demandas aparecen y las alternativas que están en esa rueda de la historia se van forjando. La agroecología puede ser encarada de esa forma, como una alternativa proveniente de la clase trabajadora campesina en beneficio de la sostenibilidad ambiental, económica, social y alimentaria humana.

\section{LA AGROECOLOGÍA COMO PROMOTOR DE DERECHOS HUMANOS}

El derecho a la agroecología puede promover numerosos derechos humanos, que incluso se elevan a derechos fundamentales, ya que están reconocidos por la Constitución brasileña. El primero de ellos es el derecho humano a una alimentación adecuada.

El derecho a la alimentación adecuada, no es tan sólo un acto de ingerir un alimento, implica prácticas alimentarias, cuestiones culturales en la preparación, valores preservados en el consumo de determinadas comidas, etc. Además, las personas tienen el derecho de acceder a los alimentos sanos y no contaminados, incluso, de forma constante. Por más que el Estado no intervenga directamente, en una práctica asistencial, entregando el alimento a familias necesitadas, debería crear mecanismos que posibiliten el acceso a ese derecho, sea instituyendo condiciones para la plantación de alimentos saludables, por medio de las semillas criollas, por ejemplo, sea realizando la reforma agraria.

El Comité de Derechos Económicos, Sociales y Culturales de la ONU, órgano responsable del monitoreo del Pacto Internacional de Derechos 
Económicos, Sociales y Culturales - PIDESC - definió en 1999, en el comentario general 12, la garantía necesaria para la alimentación adecuada humana, resaltando la importancia en que se efectúe ese derecho y la necesidad del Estado en cumplir esta meta. El artículo 11 del PIDESC, elaborado en 1966, también establece el deber de los Estados en cumplir con los medios necesarios para la efectividad de los derechos mencionados, resaltando, además, que para ese hecho, otros aspectos deben ser destacados como la educación nutricional, la reforma agraria, la valorización de recursos naturales y otros elementos verificables en el contenido del artículo. Brasil ratificó el PIDESC en 1992.

En cualquier caso, en nuestro pais hay varios dispositivos normativos en esta materia. Así, el 22 de septiembre de 2009, se aprobó, en comisión especial de la Cámara de Diputados, la Propuesta de Enmienda Constitucional (PEC - 047/2003), que incluye la alimentación adecuada entre los derechos sociales de los brasileños. Efectivamente convertida en la Enmienda Constitucional 64/2010. La Ley Orgánica de Seguridad Alimentaria y Nutricional (LOSAN), - Ley no 11.346/06 - que crea el Sistema Nacional de Seguridad Alimentaria y Nutricional que preve metas, directrices y recursos para la garantía del derecho a la alimentación adecuada. En el marco de esta norma, se puede destacar también el decreto $n^{\circ} 7.794 / 12$, - que instituye la Política Nacional de Agroecología y busca promover, entre otras cosas, la seguridad y la soberanía alimentaria.

El estímulo a la garantía de la alimentación adecuada pasa por el cultivo del alimento y, al traer el debate agroecológico, cabe destacar la importancia de las semillas criollas ${ }^{4} \mathrm{y}$ la forma que está regulado su uso.

El derecho humano a la tierra rural también debe ser enfatizado. Por intermedio de una estructura agraria latifundista y practicante del agronegocio, el derecho humano a la alimentación adecuada, o incluso a la tierra, es de difícil realización. El poder mantenido en esos pequeños grupos que concentran la tierra en el país es determinante para el mantenimiento del hambre y la falta de alternativas de vivienda y de trabajo para un inmenso número de trabajadores y trabajadoras rurales condenados tan sólo a la miseria.

El hecho de que la práctica agroecológica se desarrolla en pequeñas áreas con una diversificación agrícola y sostenibilidad en sus acciones, proveniente de un gran número de agricultores/as familiares, garantiza una mayor seguridad alimentaria y la posibilidad de permanencia del hombre/mujer en el campo, en el caso que quieran permanecer.

La reforma agraria es pauta central para la realización de derechos humanos y el advenimiento de la agroecología. "Lo que nace grande es monstruo. Lo que nace normal es pequeño" (GUTERRES, 2006, p. 17). Así, debe ser el desarrollo de la agroecología, implementado de forma transitoria y gradual, en razón del deterioro histórico corriente del suelo y de las plantas, con la amplia utilización de agrotóxicos. Así, se dará oportunidad a la producción de un gran 
número de campesinos existentes, contraponiendo la práctica latifundista, sinónimo de conflicto y de insostenibilidad.

De la misma forma que la tierra consiste en el nombre jurídico que se da a la propiedad individual, ya sea pública o privada, tenemos también el territorio como el nombre que se da a un espacio jurisdiccional, o un espacio colectivo que pertenece a un pueblo. Frente a ello, la Constitución Federal prevé el cumplimiento de la función social de la propiedad rural. Aquí, está el fundamento jurídico permite la efectividad de la reforma agraria. El análisis serio de la función social propicia verificar que el incumplimiento de ese precepto lesionará directamente un derecho fundamental establecido.

La Constitución Federal proporciona un reconocimiento jurídico-social a ese instituto, de forma explícita, debiendo cumplirse los requisitos del artículo 186 simultáneamente, pues el respeto a la función social, no es sólo por la utilización de la tierra de forma racional y adecuada. Así está dispuesto:
Art. 186. A função social é cumprida quando a propriedade rural atende, simultaneamente, segundo critérios e graus de exigência estabelecidos em lei, aos seguintes requisitos:
I - aproveitamento racional e adequado;
II - utilização adequada dos recursos naturais disponíveis e preservação do meio ambiente;
III - observância das disposições que regulam as relações de trabalho;
IV - exploração que favoreça o bem-estar dos proprietários e dos trabalhadores.

Frente a tales incisos, la propiedad rural debe estar sometida. Y con base en ellos, la fundamentación jurídica va justificarse en la lucha popular campesina que se presenta.

Además del destaque dado al derecho humano a la alimentación adecuada y a la tierra rural, aún cabe destacar categóricamente el derecho humano al medio ambiente preservado y equilibrado en una perspectiva agroecológica.

$\mathrm{Al}$ pensar en el medio ambiente, muchos elementos se destacan, como las condiciones climáticas, el agua y el aire, la alimentación, el trabajo, el ocio y varias otras cuestiones imprescindibles para el desarrollo de la vida humana. En este concepto de medio ambiente, se extrapola la característica, tan sólo, natural de la propia idea, pero también artificial, realizadas por la intervención humana concreta, y cultural, relacionadas con las costumbres, el arte, el conocimiento, la religión y otros elementos.

El derecho humano al medio ambiente es conocido como un derecho difuso, que deriva de una pluralidad de titulares, en su ejercicio, dentro de la sociedad. Además de la garantía jurídica de las personas, este derecho al medio ambiente equilibrado y preservado resguarda la vida de otros seres vivos 
que forman parte del ecosistema y que contribuyen directamente al equilibrio ambiental. No es algo convertido sólo para el ser humano, sino como ya resaltado, integra en su diversidad tanto lo natural, cuanto lo cultural y lo social.

El proceso de transformación agroecológica tiene como central esa dinámica ambiental en la transversalidad de su concepto y de su acción. La agroecología no sólo propone, como practica una agricultura ecológica, de hecho, sino también sostenible. Hoy, el término "sostenible" es a veces utilizado superficialmente, pero en el contexto aquí empleado:

(...) sustentável é a sociedade ou o planeta que produz o suficiente para si e para os seres dos ecossistemas onde ela se situa; que toma da natureza somente o que ela pode repor; que mostra um sentido de solidariedade geracional, ao preservar para as sociedades futuras os recursos naturais de que elas precisarão (BOFF; BETTO; BOGO, 2001. p. 14).

El surgimiento del concepto de sustentabilidad agroecológica contraría el modus operandi del modelo vigente. Se trata de una actividad que privilegia la producción diversificada, conviviendo con el medio natural local, no explorando el trabajo humano para su realización.

La evolución de los derechos ambientales, aunque se garantizó a nivel nacional, se desarrolló bien en el derecho internacional. Esto como consecuencia del avance de la explotación de los recursos naturales de forma desenfrenada, causada por la lógica capitalista, haciendo crecer la conciencia de algunos países ${ }^{5}$ que los recursos son finitos.

Al tratar de normas internacionales, aún existe la Declaración Universal de los Derechos Humanos, que hace la relación de una calidad de vida en el ambiente, al asegurar un nivel de vida adecuado, posibilitando mayor bienestar y salud; la ECO-92, proponente de la declaración de Río, en 1992; la Agenda 21, resaltando la importancia de la publicidad de informaciones de las cuestiones ambientales; el Protocolo de Cartagena, que busca asegurar un nivel mínimo de protección en el campo de la transferencia, manipulación y uso de los organismos vivos modificados resultantes de la biotecnología moderna que puedan tener efectos adversos en la conservación y el uso sostenible de la diversidad biológica; la Convención sobre el Cambio Climático; la Convención sobre Diversidad Biológica y varios otros Protocolos, Convenciones y Acuerdos Internacionales.

Apesar de não estar previsto em nenhum tratado internacional específico como direito humano, a referência a outros direitos humanos como a dignidade humana, saúde, trabalho, vida, bemestar, moradia, inclui necessariamente o reconhecimento do meio ambiente como direito humano, pois tudo depende dele para se realizar (LISBOA; BARROS, 2008, p. 14). 
Sin embargo, cabe presentar algunos aspectos constitucionales garantizados demostrando la aceptación de tales normas internacionales que aseguran la preservación ambiental y que legitiman la agroecología en los márgenes puestos por el derecho positivo. El artículo 225 de la Constitución Federal es la referencia legal máxima dispuesta en el ordenamiento jurídico nacional. Otras normas y, por lo tanto, las prácticas deben tener el respaldo. Por lo tanto:

Art. 225. Todos têm direito ao meio ambiente ecologicamente equilibrado, bem de uso comum do povo e essencial à sadia qualidade de vida, impondo-se ao Poder Público e à coletividade o dever de defendê-lo e preservá-lo para as presentes e futuras gerações.

Se desprende del propio caput del artículo las garantías básicas al ejercicio de ese derecho humano. El uso común del pueblo, por ejemplo, dirige un acceso justo y equitativo a los recursos ambientales disponibles en el país, democratizando los recursos y la información relacionada con ellos.

A los campesinos/as, la Constitución remite a una tarea de especial relevancia, incentivando que ellos intervengan directamente en la preservación ambiental. Así, a los agricultores agroecológicos, además de cultivar, de cuidar y de producir alimentos, cabe también luchar. Una lucha que permita la transición de una agricultura convencional depredatoria hacia una práctica agroecológica ambientalmente sustentable, conforme a la voluntad del pueblo brasileño y lo que establece la Constitución Federal.

Ciertamente, la agroecología y la eficacia de su realización contribuye en el cumplimiento de otros derechos humanos fundamentales, además de los ya enumerados en ese capítulo.

El derecho humano a la salud es un ejemplo de garantía que puede ser adquirida con la posibilidad de aplicación de dicha práctica agrícola. A partir del momento en que la producción de alimentos no hace uso de insumos y de fertilizantes químicos, ni de transgénicos, proporcionará algo más sano para la población.

Se trata del derecho a la salud derivado de una alimentación adecuada, nutritiva y benéfica. Se puede considerar, incluso, como medida relacionada a la medicina preventiva, evitando la proliferación de enfermedades relacionadas con la falta de alimentos, en razón de la agroecología garantizar un mayor acceso de la población a ellos, y previniendo las enfermedades ligadas al uso intensivo de los agrotóxicos o de semillas genéticamente modificadas rechazadas también por la práctica agroecológica.

Como el derecho humano a la salud, el trabajo también es un derecho humano dispuesto en la Constitución de la República, también como un derecho social ${ }^{6}$. El derecho humano al trabajo es referenciado en diferentes dispositivos normativos internacionales, como en la Declaración Universal de los Derechos 
Humanos (Art. XIII) y en las diversas Convenciones de la Organización Internacional del Trabajo (OIT), además de la ya citada Constitución ${ }^{7}$ y de las normas infraconstitucionales.

El trabajo vivido en el mundo del capital no parte de la valorización de la producción del trabajador/a, ni de la necesidad de los seres humanos en lo que se refiere a la producción, sino de la producción de mercancía responsable de la alienación del hombre/mujer, ya que es algo ajeno y extraño al propio hombre/ mujer, que actúa como un instrumento en la generación del producto por cuenta de la división del trabajo ${ }^{8}$. Actualmente, esa explotación de la fuerza de trabajo ocurre, incluso en el campo, con el aumento de la mecanización agrícola y el establecimiento de las empresas agrarias. La producción, cada vez más, se acerca a un brazo de la industria urbana, expulsando a un mayor número de campesinos/ as de la tierra y concentrando renta.

El trabajo como un derecho humano es considerado un derecho de las personas y un deber del Estado en respetarlo, fiscalizar sus abusos y promoverlo, preferentemente sin precarizarlo.

El fortalecimiento del campesinado y el desarrollo de la agroecología son uno de los obstáculos en este proceso de desarrollo del capital. En virtud de que se deriva de una mayor distribución de tierra y con la valorización del campesino/a que ejerce el trabajo en el campo. Ya se han presentado algunas experiencias que fortalecen la producción agroecológica, por medio de cooperativas agrícolas, por ejemplo. El hecho es que se trata de una práctica que no parte de la explotación del hombre/mujer por el hombre/mujer, siendo algo más humano y dignificante para el productor/a.

Para cumplir el derecho humano al trabajo del campesino/a, son debidas las políticas públicas que posibiliten eso. En el artículo $187^{\circ}$, la Constitución de la República del Brasil habla en el implemento de la política agrícola, algo de extrema importancia para el trabajador/a del campo. La reforma agraria o la producción en la pequeña y mediana propiedad debe ser resguardada y garantizada, ya que constituye práctica de soberanía alimentaria de la nación, con la planificación agrícola, créditos rurales dirigidos, asistencia técnica, y otras acciones garantizadoras de política agrícola. Esta política agrícola casada con la ambiental aún incluye actividades agropecuarias, pesqueras, agroindustriales y forestales, trazando la Ley no 8171/91, objetivos de protección, recuperación y preservación de los recursos ambientales disponibles.

Por medio de la implementación de esas medidas, el productor/a agroecológico tendrá condiciones reales de expansión de su producción, como consecuencia de la infraestructura propiciada y garantizado el derecho humano al trabajo digno.

Otro derecho humano básico, que incide también en la esfera de la agroecología, es la educación, y casada con ella, la información. Un pueblo 
analfabeto y sin comprensión de determinados procesos históricos es más propicio a la manipulación por aquellos que tienen tales conocimientos e informaciones. Por eso, la educación es una forma de poder.

Hoy, dentro de la propia enseñanza universitaria y de las instituciones formales de educación, hay una postura dirigida a la reproducción de la educación bajo una óptica sesgada, la cual no contribuye a la emancipación de los pueblos trabajadores. En los cursos de agronomía, por ejemplo, el contenido dominante de enseñanza es el de la agricultura convencional, pautado por el interés de las grandes empresas agroquímicas y alimenticias. La agroecología es desconsiderada en su esencia, y con ello, consecuentemente el diálogo entre los saberes. Sin embargo, sobre todo el agricultor, tiene el derecho de conocer la matriz agroecológica, si nunca ha tenido acceso a ella, para que pueda al menos optar. Algo que no sucede por la falta de acceso y de divulgación de ese tipo de conocimiento e información.

La educación debe ser capaz de promover el pleno desarrollo de las personas y responder los anhelos y las características de la comunidad, interconectando el derecho a la educación, a la práctica de derechos humanos, teniendo como base el pluralismo de ideas y de concepciones pedagógicas. Los espacios de desarrollo de la educación en respeto a los derechos humanos ya las prácticas de las comunidades pueden ser ejemplificadas por medio de las Jornadas de Agroecología, que ocurren anualmente en el Paraná, como ya se ha destacado. Los cursos de agroecología dirigidos a los pequeños agricultores/as y eventos de ese porte, todavía son pocos, a pesar de tenerse consciencia de que es importante multiplicar esas actividades y hacer que este tipo de acción pedagógica sea referencia para una política educativa del Estado.

\section{CONCLUSIÓN}

Al tratar de la agroecología, se extrapola una concepción pautada, tan sólo, en la cuestión ambiental y en la ecológica, pero se reafirma otras cuestiones como la económica, la social y la cultural, implicando en lo que conocemos como sustentabilidad. En este agroecosistema la comunidad que produce ese alimento es valorada, generando una ganancia para los campesinos productores y para las personas, hasta las de los centros urbanos, que tendrán posibilidad de alimentarse de productos con calidad y con precio asequible.

Por más que no exista la explicitación del término agroecología, todos sus fundamentos están recibidos en la Constitución Federal Brasileña y, más que eso, su práctica constituye concreta promoción de los derechos humanos. Considerando la Constitución brasileña, se buscará las garantías jurídicas debidas al desarrollo de la agroecología. Esta es la manera de construir un proyecto de país que respete a la gente. 


\section{NOTAS}

1 Art. $3^{\circ}$ Constituem objetivos fundamentais da República Federativa do Brasil:

I - construir uma sociedade livre, justa e solidária;

II - garantir o desenvolvimento nacional;

III - erradicar a pobreza e a marginalização e reduzir as desigualdades sociais e regionais;

$I V$ - promover o bem de todos, sem preconceitos de origem, raça, sexo, cor, idade e quaisquer outras formas de discriminação.

2 Art. $4^{\circ}$ - A República Federativa do Brasil rege-se nas suas relações internacionais pelos seguintes princípios:

(...)

II - prevalência dos direitos humanos;

(...).

3 El autor Ferdinand Lassalle hace algunos cuestionamientos sobre la real esencia de la Constitución, estipulándola como un conjunto de los factores reales de poder de un Estado. Para él, el cumplimiento de la Constitución depende, sobre todo, de voluntad política para ser cumplido, no vigorando la fuerza normativa, tal como lo pregonó Konrad Hess. Por lo tanto, la Constitución como mera expresión de las relaciones de poder establecidas en una determinada sociedad, no poseía fuerza jurídica, siendo tan sólo un pedazo de papel. Cf. (LASSALLE, 1985).

4 Lei no 10.711/03, Art. 2, inciso XVI - "variedade desenvolvida, adaptada ou produzida por agricultores familiares, assentados da reforma agrária ou indígenas, com características fenotípicas bem determinadas e reconhecidas pelas respectivas comunidades e que, a critério do MAPA, considerados também os descritores socioculturais e ambientais, não se caracterizem como substancialmente semelhantes às cultivares comerciais".

5 A pesar de la práctica no siempre corresponder a la retórica, pues regulan esta situación dentro de los márgenes de este modelo económico.

6 Art. $6^{\circ}$ São direitos sociais a educação, a saúde, o trabalho, a moradia, o lazer, a segurança, a previdência social, a proteção à maternidade e à infância, a assistência aos desamparados, na forma desta Constituição.

7 Art. $5^{\circ}$. XIII - élivre o exercício de qualquer trabalho, ofício ou profissão, atendidas as qualificações profissionais que a lei estabelecer;

8 "Constata-se, então, que a produção da mercadoria transformou o significado do trabalho. Antes o trabalho era uma manifestação da personalidade do homem, uma atividade humana, agora sob o crivo do capitalismo, não mais. Este desumaniza o conceito de trabalho, a partir do momento que o utiliza de forma exploratória com o intuito de gerar a mais valia" (LEONEL JÚNIOR, 2010, p. 339).

9 Art. 187. A política agrícola será planejada e executada na forma da lei, com a participação efetiva do setor de produção, envolvendo produtores e trabalhadores rurais, bem como dos setores de comercialização, de armazenamento e de transportes, levando em conta, especialmente:

I - os instrumentos creditícios e fiscais;

II - os preços compatíveis com os custos de produção e a garantia de comercialização;

III - o incentivo à pesquisa e à tecnologia;

IV - a assistência técnica e extensão rural;

$\mathrm{V}$ - o seguro agrícola;

VI - o cooperativismo;

VII - a eletrificação rural e irrigação;

VIII - a habitação para o trabalhador rural.

$\$ 1^{\circ}$ - Incluem-se no planejamento agrícola as atividades agro-industriais, agropecuárias, pesqueiras e florestais.

$\$ 2^{\circ}$ - Serão compatibilizadas as ações de política agrícola e de reforma agrária 


\section{REFERENCIAS}

ÁVILA SANTAMARÍA, Ramiro. Os direitos da natureza desde o pensamento crítico latino-americano. Revista Culturas Jurídicas, V. 4, n. 8, mai./ago., p. 17-85, 2017. Disponível em: <http://culturasjuridicas.uff.br/index.php/rcj/article/view/433/168>.

BOFF, Leonardo; BETTO Frei; BOGO, Ademar. Valores de uma prática militante. 3.ed. Cartilha ${ }^{\circ}$ 09. Consulta Popular: São Paulo, 2001.

ESCRIVÃO FILHO, Antonio. Uma hermenêutica para o programa constitucional do trabalho rural. São Paulo: Expressão Popular, 2011.

FARIA SANTOS, João Paulo. Reforma agrária e preço justo. A indenização na desapropriação agrária sancionatória. Porto Alegre. Sérgio Fabris Editor.

GUTERRES, Ivani. Agroecologia Militante: contribuições de Ênio Guterres. São Paulo: Expressão Popular, 2006;

HERRERA FLORES, J. Teoria Crítica dos Direitos Humanos. Os direitos humanos como produtos culturais. Rio de Janeiro, Lumen juris. 2009.

HESSE, Konrad. A força normativa da constituição. Tradução de Gilmar Ferreira Mendes. Porto Alegre: Sergio Antonio Fabris, 1991;

LASSALLE, Ferdinand. A Essência da Constituição. Tradução Walter Stónner. Rio de Janeiro: Líber Júris, 1985;

LEONEL JÚNIOR, Gladstone. Formas de alienação político-econômica no período da ditadura militar: a construção de falsas percepções como a figura dos "terroristas de Estado" e a ocultação do direito à verdade. In: Captura Críptica: direito política, atualidade. Revista Discente do Curso de Pós-Graduação em Direito. - n.3., v.1. (jul/dez. 2010) - Florianópolis, Universidade Federal de Santa Catarina, 2010;

LEONEL JÚNIOR, Gladstone. O novo constitucionalismo latino-americano: um estudo sobre a Bolívia. Rio de Janeiro: LumenJuris, 2015;

LEONEL JÚNIOR, Gladstone. Elementos iniciais de um direito à agroecologia. In: SOUZA, Murilo; FOLGADO, Cléber. (Org.). Agrotóxicos e Agroecologia: enfrentamentos científicos, jurídicos, políticos e socioambientais. Anápolis-GO:UEG, 2018, p. 251-260.

LISBOA, Marijane \& BARROS, Juliana Neves. Direito Humano ao meio ambiente. Plataforma Dhesca Brasil (org.). Brasília: INESC, 2008;

ROSSET. Peter. Alternativa à política fundiária de mercado: reforma agrária e soberania alimentar. In: SAUER, Sérgio \& PEREIRA, João Márcio Mendes (org.). Capturando a Terra. São Paulo: Expressão Popular, 2006; 
SOUSA JÚNIOR, José Geraldo. Direito como liberdade: o direito achado na rua. Porto Alegre: Safe, 2011;

SOUSA JÚNIOR, José Geraldo. (Coord.) O direito achado na rua: concepção e prática. Rio de Janeiro, Lumen Juris, 2015.

Submetido: $31 / 03 / 2020$

Aprovado: 29/04/2020 


\title{
LA CONSTITUCIONALIDAD DEL DERECHO A LA AGROECOLOGÍA COMO PROPULSOR DE LOS DERECHOS HUMANOS
}

\begin{abstract}
Resumen
La práctica agroecológica es una alternativa agroambiental real y viable, que se realiza garantizando la concreción de los derechos humanos. Ella cuestiona la lógica de las relaciones de poder que fundamentan la producción agrícola actual. La modificación de un modelo pautado en el agronegocio, aún amparado en la deforestación, atraviesa por transformaciones profundas en una sociedad históricamente patriarcal, latifundista, con rangos coloniales y, aún, pautada en la desigualdad. La constitucionalidad del derecho a la agroecología está fundamentada a partir de las diversas dimensiones de la vida humana, así como: la alimentación adecuada y accesible, el uso equilibrado de los recursos naturales, la preservación ambiental y la no explotación de las personas. Hay la necesidad de una modificación paradigmática del modelo agrícola con la efectividad de las prácticas agroecológicas, no sólo como un conjunto de técnicas agronómicas, sino como un proceso político-social transformador.
\end{abstract}

Palavras-chave: agroecología; derechos humanos; constitucionalidad. 


\title{
THE CONSTITUTIONALITY OF THE RIGHT TO AGROECOLOGY AS A PROPULSOR OF HUMAN RIGHTS
}

\begin{abstract}
Agroecological practice is a real and viable agri-environmental alternative, which is carried out guaranteeing the realization of human rights. It questions the logic of the power relations that underlie current agricultural production. The modification of a model based on agribusiness, still protected by deforestation, is going through profound transformations in a historically patriarchal, landowner society, with colonial ranks and, still, based on inequality. The constitutionality of the right to agroecology is based on the various dimensions of human life, as well as: adequate and accessible food, the balanced use of natural resources, environmental preservation and non-exploitation of people. There is a need for a paradigmatic modification of the agricultural model with the effectiveness of agroecological practices, not only as a set of agronomic techniques, but as a transformative political-social process.
\end{abstract}

Keywords: agroecology; human rights; constitutionality. 